\title{
DESAIN BANGKU SEKOLAH DASAR BERBASIS ANTROPOMETRI
}

\section{Gempur Santoso *)}

\section{Abstrak}

Siswa saat belajar di sekolah dasar (SD) saat ini menggunakan bangku kelas dengan ukuran yang sama, padahal ukuran antropometri siswa antar kelas berbeda. Apakah hal ini dapat dibuktikan bahwa model bangku kelas dapat didesain disesuaikan antropometri siswa, sehingga dapat dipakai sebagai rekomendasi tentang bangku sekolah secara ergonomis. Penelitian ini merupakan penelitian deskiptif. Pengambilan data secara pengukuran antropometri siswa Sekolah Dasar. Populasi dalam penelitian ini adalah siswa kelas 1-6 SD di Kecamatan Taman, Kabupaten Sidoarjo, sampel penelitian dilakukan secara acak dengan besar sampel 62 anak siswa. Metode analisis data yakni mengetahui besar perbedaan ukuran bangku berdasarkan antropometri menggunakan analisis deskriptif. Kesimpulan: bahwa bangku kelas untuk siswa Sekolah Dasar antara kelas $1-3$ dan kelas $4-6$ adalah berbeda. Siswa kelas $1-3$ harus menggunakan tinggi kursi $30 \mathrm{~cm}$, tinggi meja $43 \mathrm{~cm}$, dan lebar meja $44 \mathrm{~cm}$. Kemudian, siswa kelas $4-6$ harus menggunakan $33 \mathrm{~cm}$, tinggi meja $48 \mathrm{~cm}$, dan lebar meja $48 \mathrm{~cm}$.

Kata kunci: bangku kelas, sekolah dasar, antropometri, ergonomis

\section{Pendahuluan}

Sampai saat ini bangku belajar di sekolah tidak disesuaikan dengan antropometri usia siswa. Ketidaksesuaian bangku (alat) dengan pengguna (siswa) akan timbul berbagai dampak antara lain kelelahan siswa. Kelelahan tersebut berdampak pada penurunan daya reaksi belajar.

Hasil penelitian Gempur Santoso (2013) bahwa model bangku kelas yang ada di sekolah dasar di pedesaan Jawa Timur saat ini paling sesuai digunakan untuk siswa kelas 4 (siswa usia 9 tahun); bahwa bangku kelas untuk siswa sekolah dasar terbesar mengakibatkan keluhan pada: kaku di bagian leher bawah (rasa sangat sakit $6,3 \%$ ), pergelangan pada tangan kanan (rasa sangat sakit 6,3\%), punggung (rasa sangat sakit $13,1 \%$ ), tangan kanan (rasa sakit $26,3 \%$ ), siku kiri (rasa sakit $25 \%$ ), dan pergelangan kaki kiri (rasa sakit 25\%).

Terkait dengan hasil produk (bangku) yang tidak didasarkan antropometri siswa, menurut hasil penelitian Woro (2001) "ternyata $(100 \%)$ meja dan $(81,11 \%)$ kursi untuk anak sekolah di Indonesia tidak ergonomis". Artinya bahwa desain meja dan kursi sekolah yang telah diproduksi tidak sesuai dengan dimensi antropometri peserta didik. Dampaknya menurut Woro (2001) adalah "gangguan kesehatan pada peserta didik antara lain pusing dan pegal/sakit $(72,3$ $\%)$, anak merasa lelah $(65,4 \%)$, dan leher pegal/sakit (61,3 \%)". Hal ini menunjukkan bahwa desain produk berupa barang mutlak harus disesuaikan dengan dimensi antropometri agar ergonomis. Begitu pula hasil penelitian Gempur (2007) menunjukkan bahwa "kursi dan meja ergonomis dapat menurunkan kelelahan sebesar 8,5\%".

Kegiatan belajar mengajar bagi siswa duduk di kelas membutuhkan waktu lama antara 4- 7 jam sehari. Menurut Alan Glaser (2001) "duduk lama dan statis akan menimbulkan ketegangan pada vertebralis terutama pada lumbar". Juga, "bila tinggi kursi terlalu pendek, duduk akan membungkuk, karena lutut akan lebih tinggi dibanding posisi pantat, akibatnya pelvic merenggang, columna spinal tegang, abdomen bawah menekan dan sirkulasi gerakan terbatas, serta lambat laum terjadi nyeri dan lelah" Alan Glaser (2001). Dalam keadaan lelah maka daya reaksi berfikir akan mengalami penurunan. Penurunan daya reaksi berfikir tersebut menupakan kelahan syaraf.

Di sisi lain, bahwa sampai saat ini ukuran bangku sekolah disamakan antara siswa SD kelas satu sampai kelas enam. Padahal, antropometri antara siswa SD kelas satu sampai kelas enam adalah berbeda. Oleh karena itu, sangat mungkin siswa SD di seluruh Indonesia saat ini mengalami kelelahan karena faktor bangku belajar.

Penelitian ini ingin membuktikan bahwa bangku sekolah yang ergonomis dapat menurunkan kelelahan siswa. Desain ergonomis tersebut bersasarkan ukuran tubuh (antropometri) siswa.

*) Dosen Teknik Industri

Universitas PGRI Adi Buana Surabaya

Rata-rata percentile ukuran tubuh (antropomeri) usia siswa antar tingkat kelas 
adalah berbedada, tetapi sampai saat ini diberikan bentuk dan ukuran bangku yang sama. Ketidaksesuaian bangku sekolah dengan antropometri merupakan stressor keluhan siswa, yang selanjutnya adalah penurunan tingkat daya reaksi belajar siswa. Desain model bangku kelas ergonomis sebagai alternatif solusi dimungkinkan dapat meniadakan keluhan dan kelelahan siswa.

Masalah Penelitian

Siswa saat belajar di sekolah dasar (SD) saat ini menggunakan bangku kelas dengan ukuran yang sama. Apakah hal ini dapat dibuktikan bahwa model bangku kelas dapat didesain disesuaikan antropometri siswa, sehingga dapat dipakai sebagai rekomendasi tentang bangku sekolah secara ergonomis.

\section{Metode Penelitian}

Penelitian ini merupakan penelitian deskiptif dilakukan pengambilan data secara obsevasional (pengukuran) uantuk mengetahui antropometri siswa Sekolah Dasar. Populasi dalam penelitian ini dirancang (terencana) adalah siswa kelas 1 sampai dengan siswa kelas 6 Sekolah Dasar di Kecamatan Taman, Kabupaten Sidoarjo. Teknik sampel dalam penelitian ini dilakukan secara acak dengan besar sampel 62 anak siswa SD kelas $1-6$.

Metode pengumpulan data yang digunakan adalah melakukan pengukuran antropometri psisi duduk dan berdiri. Untuk menganalis data yakni mengetahui besar perbedaan ukuran bangku berdasarkan antropometri menggunakan analisis deskriptif.

\section{Analisis dan Pembahasan}

Data hasil pengukuran antropometri siswa sekolah dasar (SD) dapat dilihat pada tabel 1 dan tabel 2. Data tersebut dibuat dua kelompok yakni antropometri siswa laki-laki dan perempuan kelas $1-3$ (usia 6 tahun -8 tahun); serta kelas $4-6$ (usia 9 tahun -11 tahun).

Tabel 1. Antropometri Laki-Laki dan Perempuan Usia 6 tahun - 8 tahun

\begin{tabular}{|c|c|c|c|c|c|}
\hline \multirow[t]{2}{*}{ No } & \multirow[t]{2}{*}{ Jenis Antropometri } & \multirow[t]{2}{*}{ Rata-rata } & \multirow{2}{*}{$\begin{array}{l}\text { Std. } \\
\text { Dev }\end{array}$} & \multicolumn{2}{|c|}{ Percentile } \\
\hline & & & & $5 \%(\mathrm{~cm})$ & $\begin{array}{l}95 \% \\
(\mathrm{~cm})\end{array}$ \\
\hline 1 & Tinggi lulut (TL) & 38,60 & 3,49 & 33,00 & 44,85 \\
\hline 2 & Tinggi lutut punggung (LLP) & 35,02 & 4,44 & 29,15 & 39,85 \\
\hline 3 & Tinggi duduk (TD) & 98,52 & 9,22 & 80,30 & 109,85 \\
\hline 4 & Lipat lutut telapak kaki (LLTK) & 33,81 & 2,71 & 30,00 & 38.00 \\
\hline 5 & $\begin{array}{l}\text { Panjang lengan bawah dan lengan } \\
\text { (PLBL) }\end{array}$ & 56,24 & 6,69 & 44,15 & 67,00 \\
\hline 6 & Tinggi badan (TB) & 119,77 & 9,72 & 103,30 & 134,00 \\
\hline 7 & Tinggi bahu (TBH) & 97,32 & 9,12 & 82,00 & 109,85 \\
\hline 8 & Tinggi pinggul (TPG) & 72,69 & 4,59 & 65,00 & 81,70 \\
\hline 9 & Tinggi siku (TS) & 74,48 & 6,82 & 66,15 & 84,85 \\
\hline 10 & Depa (DP) & 118,66 & 9,64 & 104,00 & 134,85 \\
\hline 11 & Panjang lengan (PLNG) & 48,58 & 3,48 & 44,00 & 55,00 \\
\hline
\end{tabular}


Tabel 2. Antropometri Laki-Laki dan Perempuan Usia 9 tahun - 11 tahun

\begin{tabular}{|c|c|c|c|c|c|}
\hline \multirow[t]{2}{*}{ No } & \multirow[t]{2}{*}{ Jenis Antropometri } & \multirow[t]{2}{*}{ Rata-rata } & \multirow{2}{*}{$\begin{array}{l}\text { Std. } \\
\text { Dev. }\end{array}$} & \multicolumn{2}{|c|}{ Percentile } \\
\hline & & & & $5 \%(\mathrm{~cm})$ & $\begin{array}{l}95 \% \\
(\mathrm{~cm})\end{array}$ \\
\hline 1 & Tinggi lulut (TL) & 44,81 & 3,63 & 38,00 & 50,00 \\
\hline 2 & Tinggi lutut punggung (LLP) & 40,88 & 3,98 & 35,00 & 49,00 \\
\hline 3 & Tinggi duduk (TD) & 109,36 & 5,83 & 100,00 & 118,00 \\
\hline 4 & Lipat lutut telapak kaki (LLTK) & 38,37 & 3,38 & 33,00 & 44,00 \\
\hline 5 & $\begin{array}{l}\text { Panjang lengan bawah dan lengan } \\
\text { (PLBL) }\end{array}$ & 63,75 & 6,17 & 54,00 & 73,00 \\
\hline 6 & Tinggi badan (TB) & 136,81 & 9,72 & 119,00 & 152,00 \\
\hline 7 & Tinggi bahu (TBH) & 113,46 & 9,49 & 96,00 & 127,00 \\
\hline 8 & Tinggi pinggul (TPG) & 84,58 & 6,88 & 74,00 & 97,00 \\
\hline 9 & Tinggi siku (TS) & 86,85 & 6,13 & 74,00 & 96,00 \\
\hline 10 & Depa (DP) & 137,25 & 10,54 & 121,00 & 156,00 \\
\hline 11 & Panjang lengan (PLNG) & 54,88 & 3,62 & 48,00 & 61,00 \\
\hline
\end{tabular}

Berdasarkan hasil pengukuran antropometri di atas (tabel 1, dan 2) diperlihatkan bahwa terdapat dua kelompok antropometri yakni siswa kelas 1 dan kelas 3 (usia 6 tahun -8 tahun), serta siswa kelas 4 dan kelas 6 (usia 9 tahun - 11 tahun). Guna keperluan desain produk bangku kelas diantaranya diperlukan beberapa ukuran yakni: 1) tinggi kursi, 2) tinggi meja, dan 3) lebar meja.

Untuk keperluan desain ergonomis, maka ukuran bangku kelas tersebut harus disesuaikan antropometri pengguna (siswa). Kesesuan ukuran bangku kelas dengan antropometri adalah sebagai berikut:

1) Tinggi kursi disesuaikan lipat lutut telapak kaki (LLTK) precentile $5 \%$, agar siswa antropometri kecil dapat mudah naik duduk di kursi, dan siswa yang antropometri besar juga mudah naik duduk di kursi.

2) Tinggi meja disesuaikan tinggi lutut $(\mathrm{TL})+10 \mathrm{~cm}$ percentile $5 \%$. Penambahan $10 \mathrm{~cm}$ tujuannya agar ketika duduk lutut dan paha dapat masuk di bawah meja, dan percentile $5 \%$ agar siswa antropometri kecil tidak terlalu tinggi mejanya, dan siswa yang antropometri besar juga nyaman dengan meja tersebut.

3) Lebar meja disesuaikan dengan panjang lengan (PLNG) percentile $5 \%$, agar siswa antropometri kicil dan besar dapat menjangkau tangannya saat menggunakan meja tersebut.

Bentuk bangku kelas yang disesuaikan antropometri dapat dilihat pada gambar 1 di bawah ini. 


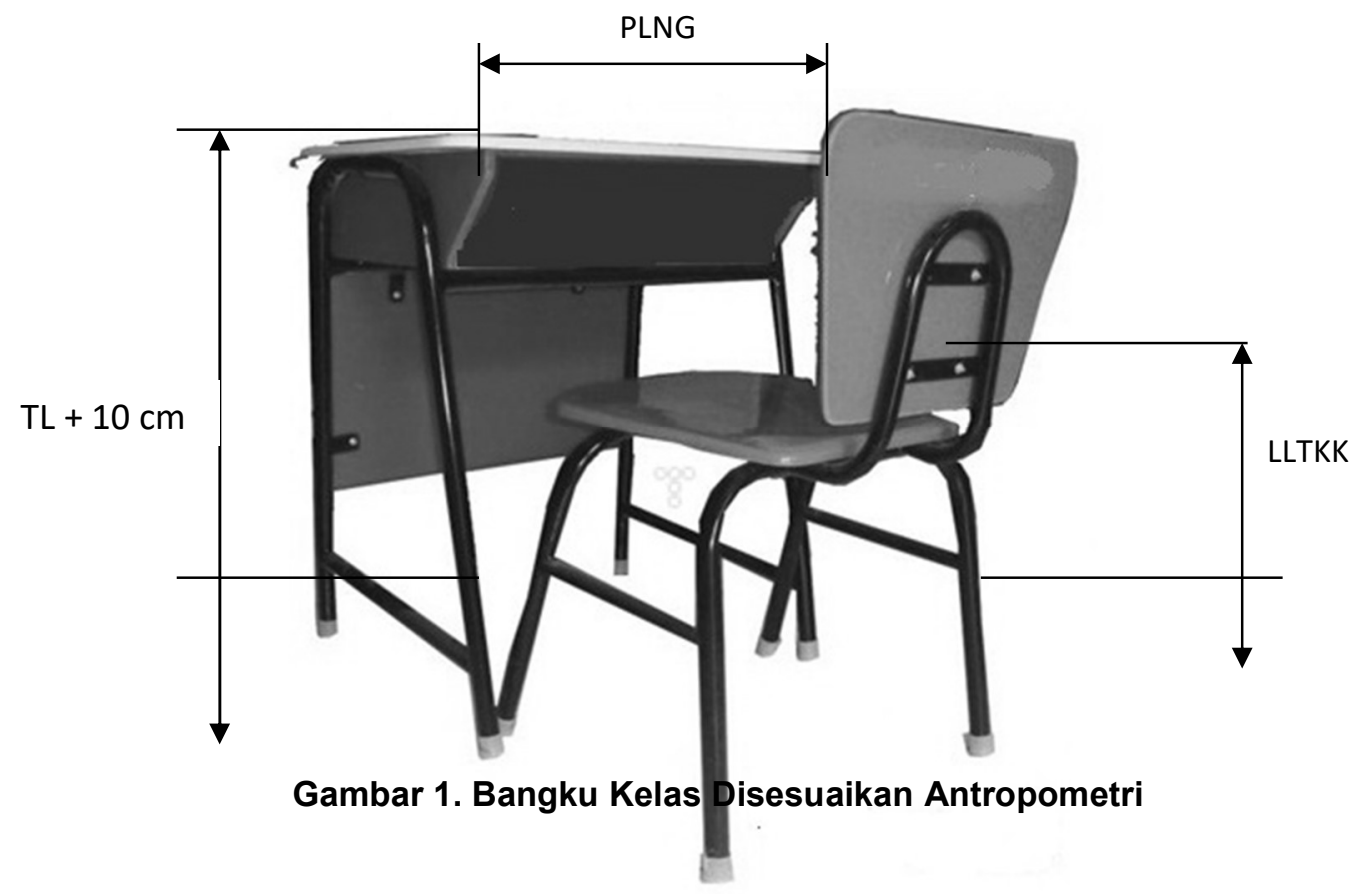

Berdasarkan tabel 1 dan tabel 2 di atas, terdapat selisih percentile pada antropomeri antara siswa kelas $1-3$ dan siswa kelas $4-6$. Selisih perbedaan antropometri tersebut sebagai berikut:

Tabel 3. Selisih ukuran bangku kelas disesuaikan antropometri antara siswa kelas 1 kelas 2 dan kelas 4 kelas 6

\begin{tabular}{|c|l|l|l|c|}
\hline No & $\begin{array}{l}\text { Jenis ukuran bangku } \\
\text { di sesuaikan } \\
\text { Antropometri }\end{array}$ & $\begin{array}{c}\text { Ukuran bangku } \\
\text { siswa kelas 1-3 } \\
\text { (cm) }\end{array}$ & $\begin{array}{c}\text { Ukuran bangku } \\
\text { siswa kelas 4-6 } \\
\text { (cm) }\end{array}$ & $\begin{array}{c}\text { Selisih } \\
\text { ukuran } \\
\text { (cm) }\end{array}$ \\
\hline 1 & $\begin{array}{l}\text { Tinggi kursi } \\
\text { disesuaikan } \\
\text { (percentile 5\%) }\end{array}$ & 30 & 33 & 3 \\
\hline 2 & $\begin{array}{l}\text { Tinggi meja } \\
\text { disesuaikan TL + 10 } \\
\text { cm (percentile 5\%) }\end{array}$ & $\begin{array}{l}\text { Lebar 10 } 33+43 \\
\text { disesuaikan PLNG } \\
\text { (percentile 5\%) }\end{array}$ & $38+10=48$ & 4 \\
\hline
\end{tabular}

Berdasarkan tabel 3 di atas, diperlihatkan bahwa tinggi kursi siswa kelas 1 - 3 seharusnya lebih pendek $3 \mathrm{~cm}$ dari pada siswa kelas $4-5$, atau sebaliknya. Tinggi meja kelas siswa kelas $1-3$ seharusnya lebih pendek $5 \mathrm{~cm}$ dibanding siswa kelas 4 - 6, atau sebailinya. Juga, lebar meja kelas siswa kelas 1 - 3 seharusnya lebih kecil dibanding siswa kelas $4-6$.

Ketidak sesuian bangku belajar dengan antropometri siswa tersebut akan mempercepat kelelahan siswa saat belajar di kelas. Hal itu sebagaimana juga menurut
Alan Glaser (2001). "bila tinggi kursi terlalu pendek, duduk akan membungkuk, karena lutut akan lebih tinggi dibanding posisi pantat, akibatnya pelvic merenggang, columna spinal tegang, abdomen bawah menekan dan sirkulasi gerakan terbatas, serta lambat laum terjadi nyeri dan lelah"

\section{Kesimpulan}

bahwa bangku kelas untuk siswa Sekolah Dasar (SD) antara kelas 1 - 3 dan kelas $4-6$ adalah berbeda. Siswa kelas $1-$ 3 harus menggunakan tinggi kursi $30 \mathrm{~cm}$, tinggi meja $43 \mathrm{~cm}$, dan lebar meja $44 \mathrm{~cm}$. 
Kemudian, siswa kelas $4-6$ harus menggunakan $33 \mathrm{~cm}$, tinggi meja $48 \mathrm{~cm}$, dan lebar meja $48 \mathrm{~cm}$. Ketidaksesuaian ukuran bangku kelas dengan antropometri pengguna (tidak ergonomis) akan mempercepat kelelahan.

Saran berdasarkan kesimpulan di atas, diharapkan bagian pengadaan sarana dan prasarana bangku kelas untuk sekolah dasar (SD) dalam memesan bangku kelas sesuaikan sesuai antropometri, yang ukurannya seperti hasil penelitian ini.

\section{DAFTAR PUSTAKA}

Alan Glaser, 2001, The vital role of seating in back care, Positive Health Publications Ltd, London

Dewa Putu Sutjana, 2000, Penuntun tugas lapangan matakuliah fisiologi kerja, Program Pascasarjana, Universitas Udayana Bali.

Eko Nurminto.2003. Ergonomi Konsep Dasar Aplikasi, Surabaya: Prima Printing.

Gempur Santoso, 2007, Kursi meja kerja ergonomis untuk posisi duduk statis, Karya Inovatif Perguruan Tinggi, DP2M - Dikti - Depdiknas, 2007: hal. 198, Jakarta

Gempur Santoso, 2008, Deteksi kelelahan pada kerja bubut posisi berdiri terhadap fluktuasi asam laktat dan glukosa, Wahana Jurnal ilmiah sains \& ilmu pendidikan, volume 51 nomor 1, juni 2008, hal: 19-26, Unipa Surabaya

Gempur Santoso, 2013, Model bangku kelas terhadap Respons keluhan pada siswa (penelitian observasional ergonomis pada siswa sekolah dasar), Laporan Penelitian, LPPM Universitas PGRI Adi Buana Surabaya.

Julius Panero,dkk, 2003, Dimensi Ruangan Manusia Dan Ruangan Interior, Erlangga, Jakarta.

Mohammad Sholeh, 2000, Pengaruh Shalat Tahajjud Terhadap Peningkatan Perubahan Respon Ketahanan Tubuh Imunologik, Disertasi, Pascasarjana Unair, Surabaya.

M. Aron Pase, 2006, Shalat Tahajjud Menyehatkan Anda, SEDOTAN LIMUN.htm, Copyright @ 2006 Dhody (sedotan limun@yahoo.co.id)

Peter A. Mayes, 1999, Boikimia Harper, Edisi 24, EGC, Jakarta.

Poppy Anjelisa Z. Hsb, 2008, Kelelahan, Analisadaily.com, http://kolector.blogspot.com/2009/10/kelelahan.html

Rungtai Lin and Yen-Yu Kang, 2009, Ergonomic Design of Desk and Chair for Primary School Students in Taiwan, Department of Industrial Design, Mingchi Institute of Technology, Taishan, Taipei Hsien Taiwan, 243, HTUrtlin@mail.mit.edu.twUTH ven@ccsun.mit.edu.tw

Sigit Wasi W, 2005, Bekerja Dengan Komputer secara ergonomis dan sehat. www.wahanako.com

Woro Riyadina, 2001, Dampak meja kursi sekolah yang tidak ergonomis terhadap kesehatan anak sekolah, Balitbang Dikdasmen Dikti, Departemen Pendidikan Nasional, Jakarta. 